\title{
Numerical studies on perforation of multi-layered targets by hemispherical-nosed projectiles
}

\author{
B Ramakrishna, Dr.T.V.K Bhanu Prakash \\ Andhra University, Vishakapatnam, India
}

\begin{abstract}
In the present work, the ballistic performance of monolithic, in-contact and spaced type layered configurations of aluminium 1100 plates impacted by hemispherical-nosed projectiles was investigated. Numerical simulations were carried out to study the failure modes and ballistic performance of Al 1100 targets subjected to normal and oblique impact $\left(0^{\circ}, 15^{\circ}\right.$ and $\left.30^{\circ}\right)$ of hemispherical-nosed projectiles. The explicit Autodyn FEM code was employed to carry out the numerical simulations. A study has been undertaken to assess the effect of element size and its aspect ratio in numerical simulations.

The ballistic performance of monolithic target was found to be better at higher velocities than in-contact type target plates. The ballistic resistance of spaced type targets was observed to be less due to small contact force between layers. The reduction of spacing from $5 \mathrm{~mm}$ to $1 \mathrm{~mm}$ between the layers improved the ballistic resistance substantially due to large interaction force. It was concluded that obliquity effect in this study had significant influence on the response of target. At each angle of impact the ballistic resistance of monolithic target was found slightly better than that of other configurations. The variation in the deformation of target plates with radial distance from the center of the plate is also presented. At each radial distance of from the center of the plate for in-contact target plates, the deformation of target was found to be higher as compared to spaced target plates.
\end{abstract}

Keywords: Al 1100; Layered Plates; Numerical Simulation; Perforation.

\section{Introduction}

Aluminium alloys have been used widely as armor materials due to low density and superior ballistic properties. Several investigations have been made on aluminium alloys against various small and medium caliber projectiles. Even though experimental approach gives most exact results, an iterative procedure involving dynamic material testing and computer modeling may reduce the time and expense required for the development of advanced materials for applications such as armor. The simulated data obtained will be helpful for the purpose of design of products as well as for assessing the mechanism of penetration.

The impact of projectiles on monolithic and multi-layer targets has attracted the attention of many researchers [1-5], while developing protective systems against various threat levels. The improvement of multi layer target design is essential for enhancing the resistance of the target and reducing the weight of the target. Many researchers have studied the response of aluminium alloys against various threat levels and loading conditions. Ozsahin [6] investigated the effect of surface coating on the ballistic performance of three aluminium alloys $(2024,6061$ and 7075) experimentally. It has been found that zirconium oxide coating enhances the depth of penetration. Palleti et al. [7] carried out ballistic impact experiments on metallic targets to study different mechanisms of energy absorption. The analysis comprises plug formation and plastic penetration for evaluating velocity and energy of the projectile during impact. Flores-Johnson et al. [8] performed numerical investigation of layered metallic plates impacted by 7.62AP projectile. FEM code LS-DYNA was used to develop numerical model. It was observed that single layer plates had superior ballistic resistance than multi layered plates. Gupta et al. [9] conducted ballistic experiments on aluminum targets by various shapes of steel projectiles. Different failure mechanisms like plugging, tearing and thinning of target plates were discussed. ABAQUS FEM code was employed to perform numerical modeling. Jena et al. [10] investigated the penetration mechanism of metal-metal and metal-fabric layered structures against 7.62 armor piercing projectiles. Failure and fracture mechanisms of the samples were studied by using electron microscopy, X-ray radiography and hardness measurements. Borvik et al. [11] performed gas gun experiments on weldox 460E steel plates against different nose shape projectiles to determine residual velocity and energy absorption of target plate. It was observed that the nose shape of the projectile had influence on the energy absorption mechanism of the target plate. Gupta et al. [12] studied the effect of normal and oblique impacts of hard core projectile on single and multi-layered targets.Relations were established between residual velocity of the projectile and hardness of the target materials. Wei [13] et al. performed impact experiments on monolithic and layered metal plates to evaluate the ballistic performance using gas gun by blunt rigid projectiles. The effect of air gap between layers and thickness was also studied. The ballistic performance of monolithic plates was found to be superior to layered plates. Deng [14] et al. investigated the ballistic performance of layered steel plates impacted 
by ogive nosed projectiles. The influence of air gap between layers, order and thickness of layers on ballistic performace of targets was also discussed.

The available literature has so far dealt with modeling of impact on single and multiple layered target plates for different projectile nose shapes at various impact velocities. No attempt has been made to undertake the numerical modeling of perforation of in-contact and spaced type multi layered plates against hemispherical nosed projectiles impacted at oblique angles. The main objective of this research is to present the numerical modeling aspects on perforation of Al 1100 target of in-contact and spaced type layered configurations against hemispherical nosed projectiles at $0^{\circ}, 15^{0}$ and $30^{\circ}$ impact angles.

Effect of important parameters such as element size and aspect ratio on the numerical results was also investigated. The variation of the deformation of target plates for different configurations from the center of the plates in the radial direction was also discussed.

\section{Problem description and model validation}

Aluminium alloy 1100 in various configurations of in-contact type and spaced type targets has been impacted by hemi spherical projectiles using numerical simulations. The numerical simulations have been performed using Ansys Autodyn code. The Lagrange processor was used to represent both projectile and target. The Lagrangian scheme in numerical simulation requires an artificial technique to treat large deformation called erosion technique. Degenerated cells were eroded at an instantaneous geometric strain rate equal to 1.5. Fig.1 depicts the material modeling of target plate against hemi spherical projectile for the target plate. LagrangeLagrange contact impact algorithm was employed between the target and projectile. Residual velocity of the projectile of the plate was evaluated by the simulated data.

The initial element size of each target plate was selected as $1.5 \times 1.5 \times 1.5 \mathrm{~mm}$, of 3 elements along the thickness of each target plate. Meshing of Al 1100 target plate was carried out to obtain exact results within minimum computational time. The aspect ratio of elements was varied from 0.5 to 2.5 (fig.2). Convergence study was undertaken to determine the optimum size of the element for obtaining a proper solution. The number of elements in the target plate was varied from 3 to 8 in the impact region. The target plate was meshed with the above six mesh patterns and impacted by hemi spherical projectile at a velocitity ranges between 110 and 140 $\mathrm{m} / \mathrm{s}$. It was observed that the residual velocity of projectile increased up to 6 elements and then it became almost constant (fig. 3). The total number of elements was taken as 6 in the target plate and corresponding element size $0.2 \times 0.2 \times 0.2 \mathrm{~mm}^{3}$ for all numerical simulations in this investigation. The influence of significant variables such as element size as well as its aspect ratio on the simulation results was also discussed. The influence of friction between the projectile and target was found to be negligible. This was confirmed by taking two values of friction as 0.0 and 0.05 but no considerable difference was noticed in the simulation results.Projectile is modeled with hexahedral meshing. The behavior of the target plate is simulated using Johnson-Cook model [15-18] and the material constants. Numerical simulations are performed using fine mesh of different mesh sizes for the target plate.

(i) Very fine $-0.2 \mathrm{~mm} \times 0.2 \mathrm{~mm} \times 0.2 \mathrm{~mm}$.

(ii) Fine $-0.5 \mathrm{~mm} \times 0.5 \mathrm{~mm} \times 0.5 \mathrm{~mm}$.

(iii) Coarse $-1 \mathrm{~mm} \times 1 \mathrm{~mm} \times 1 \mathrm{~mm}$.

(iv) Very coarse $-1.5 \mathrm{~mm} \times 1.5 \mathrm{~mm} \times 1.5 \mathrm{~mm}$.

Table 1 presentss the layer codes for different layer thicknesses. The hard steel projectile was considered as rigid body with 5436 brick elements. The target plate movement was restricted with fixed boundary condition. Plate deformation, plastic strain, Von-mises stresses and energy absorption profiles were recorded. Velocity in the normal direction to projectile axis is caused by "mushrooming" effect. It is attributed to the lowest yield stress caused large ductility. AUTODYN estimates the energy balance, both kinetic and internal energy steadily reduce as the elements erode. This causes an energy balance error. Energy error found to be large at coarse mesh sizes. Fine mesh or enhancing the value of energy error in the problem definition will alleviate this problem. The hemi-spherical projectile was created with a diameter of $8 \mathrm{~mm}$ and, the total length of the projectile was $30 \mathrm{~mm}$. Fig. 8 illustrates a finite element model of projectile and spaced type target. "Clamped" boundary condition was applied to the target plate for arresting its movement in all degrees of freedom. Interaction between projectile and the target plate was achieved using the gap interaction technique [20]. The gap size has been set as $0.12 \mathrm{~mm}$.

\section{Results and discussion}

The hard steel projectiles did not fail during perforation and most of the kinetic energy of the projectiles was absorbed through plastic deformation of target plate. Von-mises stress (fig.4), plastic strain, and energy absorption profiles were obtained from Autodyn simulations. From numerical simulations of projectile impact on target plates, it is observed that most part of input energy is dissipated through localized plastic 
deformation (fig.6). The deformation mechanism is attributed to shear formation due to large momentum. The amount of plastic deformation of target gets reduced with the impact velocity. Equivalent plastic strain and vonmises stress in the plate enhanced as the projectile penetrated the plate, and attained maximum values at failure. Peak values of stress and plastic strain were achieved when deformed materials separated from the target plate (fig.7). Once failure commenced, the value of the von-mises stress declined. It was also understood that locations of max shear stress and von-mises stress are identical. The ability of energy absorption of target plate enhances with an increase in the projectile impact velocity and target thickness. The amount of the plastic strain increased with the initiation of penetration. Most portion of the kinetic energy of the projectile was expended in plastic deformation of the target material before perforation (Fig. $13 \&$ 14). Following the impact of the projectile the internal energy increases at the expense of kinetic energy of the projectile. The kinetic energy of the projectile is determined by summation of the product of mass and square of nodal velocity. The energy loss is caused due to the deceleration of projectile. Once the front layer is perforated, the next layer has to absorb the residual energy of the projectile by deforming and local bending and converting deformed energy to heat energy. This is due to bending effect which induces an increase of plastic work. For high impact velocity the failure appears quickly without bending effect and in this case the plastic work is lower. It was also observed that monolithic plates showed superior bending resistance compared to other configurations (Fig.5). At lower thickness 0.15 , land $1.5 \mathrm{~mm}$, the main mode of failure was stretching. Whereas at higher thicknesses $2,2.5$ and $3 \mathrm{~mm}$, plug removal through shearing was observed. Bending also contributed to the failure of target plate due to the generation of tensile stresses at the contact region. The ability of energy absorption of aluminuim plate enhances with an increase in the projectile impact velocity and target thickness.

Hemispherical nosed projectile created severe stress concentration. Plastic strain and von-mises stress in the aluminium plate enhanced as the projectile penetrates the plate, and attained maximum values at failure and subsequently maintained constant. The amount of the plastic strain increased with the initiation of penetration. Hemispherical nosed projectile needed more energy because of its less tearing tendency. Most portion of the kinetic energy of the projectile was expended in plastic deformation of the target material before perforation.

Fig. $15 \& 16$ demonstrate the comparision of the results obtained from the numerical study with the experimental values performed by Alavi Nia et al. [19] on triple layered target of different thickness plates of spaced type. The ballistic limit of the projectile was observed to be $48.0 \mathrm{~m} / \mathrm{s}$ from the numerical study and 46.9 $\mathrm{m} / \mathrm{s}$ from the experimental investigaton. For the in-contact type triple layered configuration, the ballistic limit of the projectile was found to be $48.0 \mathrm{~m} / \mathrm{s}$ from the numerical study and $46.9 \mathrm{~m} / \mathrm{s}$ from the experimental investigaton. The residual velocity of single plate of $3 \mathrm{~mm}$ thickness was found to be the lowest followed by layered in-contact. The ballistic performance of monolithic target was found to be better at higher velocities than in-contact type target plates. The ballistic resistance of spaced type targets was observed to be less due to small contact force between layers. The ballistic performance of triple layered plates was also influenced by spacing and order of layers. The reduction of spacing from $5 \mathrm{~mm}$ to $1 \mathrm{~mm}$ between the layers improved the ballistic resistance substantially due to large interaction force (Fig.9 \& 10).

It has been found that the maximum amount of the kinetic energy of hemi-spherical nosed projectile is absorbed by global bending and strectching of the target due to higher tensile strains. The amount of plastic deformation has also been found to be significant at higher velocities, which has been verified by the energy profiles obtained from numerical simulations. The bending energy was determined from the following energy balance equation.

$\mathrm{E}_{\text {bending }}=\mathrm{E}_{\text {total }}-\mathrm{E}_{\text {residual }}-\mathrm{E}_{\text {plastic deformation }}$

The variation of the ballistic performance is attributed to the transformation of the failure mode from in-contact type to spaced type configurations. The behavior of target plates during impact is predominantly due to tensile strains, the kinetic energy of the projectile is dissipated as plastic deformation and global bending of the target plate. The deflection of the target plate is found to be higher than the target thickness. From fig.10, it is noticed that at higher impact velocities maximum deflection of the target plate is found to be less due to the reduction of the time available to traverse the target. An attempt hase been made to present the numerical modeling aspects on perforation of $\mathrm{Al} 1100$ target of in-contact and spaced type layered configurations against hemispherical nosed projectiles at $0^{0}, 15^{0}$ and $30^{\circ}$ impact angles (Fig. 11\&12). Autodyn simulations for aluminium targets were performed at $15^{\circ}$ and $30^{\circ}$ obliquity angles as presented in table 2 and 3 . Numerical simulations in oblique impact revealed that during perforation of the target the projectile deviated from the straight path. The residual velocity of projectile decreased by $8 \%$ and $7 \%$ for $15^{\circ}$ and $30^{\circ}$ impact angles respectively. It was concluded that obliquity effect in this study had significant influence on the reponse of target. At each angle of impact the ballistic resistance of Monolithic target was found slightly better than that of other configurations. Fig. 17 depicts the variation in the deformation of target plates with radial distance from the center of the plate for T1T2T3 configuration. Fig. 18 demonstrates the variation in the deformation of the 
target plate for T3T2T1 configuration. While at each radial distance of from the center of the plate for in-contact target plates, the deformation of target was found to be higher as compared to spaced target plates (Fig.19).

\section{Conclusions}

This paper discussed 2D and 3D finite element models for normal and oblique imact of hemi spherical projectiles on aluminium target plates of in-contact and spaced type configurations. The conclusions are as follows:

- The ballistic performance of monolithic target was found to be better at higher velocities than in-contact type target plates. The ballistic resistance of spaced type targets was observed to be less due to small contact force between layers.

- The ballistic performance of triple layered plates was influenced by spacing and order of layers. The reduction of spacing from $5 \mathrm{~mm}$ to $1 \mathrm{~mm}$ between the layers improved the ballistic resistance substantially due to large interaction force. It has been found that the maximum amount of the kinetic energy of hemispherical nosed projectile is absorbed by global bending and strectching of the target due to higher tensile strains.

- Numerical simulations in oblique impact revealed that the residual velocity of projectile decreased by $8 \%$ and $7 \%$ for $15^{\circ}$ and $30^{\circ}$ impact angles respectively. It was concluded that obliquity effect in this study had significant influence on the reponse of target. At each angle of impact the ballistic resistance of monolithic target was found slightly better than that of other configurations.

- The variation in the deformation of target plates with radial distance from the center of the plate is also presented. At each radial distance of from the center of the plate for in-contact target plates, the deformation of target was found to be higher as compared to spaced target plates.

- The predicted residual velocities were in good agreement with experimental results. Simulated failure modes of the target plates were compared with experimental results and found well.

The present inverstigation demonstrates that the mechanism of perforation of in-contact and spaced configurations is pretty complex. The deformation mechanism of target plates is not fully analysed. Further reseasrch is essential to understand the deformation phenomena for various configurations of different impact angles.

\section{Acknowledgements}

The authors would like to thank DRDO, India for financial help in carrying out the experiments. The authors express their gratitude to Director, DMRL for giving permission to publish this work.

[1] Borvik T, Clausen A H, Eriksson M, Berstad T, Hopperstad O S, Langseth M.Experimental and numerical study on the perforation of AA6005-T6 panels. Int J of Impact Eng 2005; 32:35-64.

[2] Gupta NK, Iqbal MA, Sekhon GS. Effect of projectile nose shape, impact velocity and target thickness on the deformation behaviour of layered plates. Int J Impact Eng 2008; 35:37-60.

[3] Bovik T, Hopperstad OS, Berstad T, Langseth M. Perforation of $12 \mathrm{~mm}$ thick steel plates by $20 \mathrm{~mm}$ diameter projectiles with flat, hemispherical and conical noses. Part II: numerical simulations. International Journal of Impact Engineering 2002;27(1):37-64.

[4] Dey S, Bovik T,Teng X, Wierzbicki T, Hopperstad OS. On the ballistic resistance of double-layered steel plates: an experimental and numerical investigation. International Journal of Solids and Structures 2007; 44:6701-23.

[ 5] Borvik T, Langseth M, Hopperstad O S, Malo K A. Perforation of $12 \mathrm{~mm}$ thick steel plates by $20 \mathrm{~mm}$ diameter projectiles with flat, hemispherical and conical noses Part I: Experimental study. Int J Impact Eng. 2002; 27: 19-35.

[ 6] Ozsahin E, Tolun S. On the comparison of the ballistic response of coated aluminium alloys. Maternd design 2010; 31:3188-3193.

[7] Palleti H N K T, Gurusamy S, Kumar S, Soni R, John B, Vaidya R, Bhoge A, Naik N K. Ballistic impact performance of metallic targets. Mater and design 2012; 39:253-263.

[ 8] Flores-Johnson E A, Saleh M, Edwards L. Ballistic performance of multiayered metallic plates impacted by a 7.62-MM APM2 projectile. Int J of Impact Eng 2011; 38:1022-1032.

[9] Gupta N K, Iqbal M A, Sekhon G S. Effect of projectile shape, impact velocity and target thickness on deformation behaviour of aluminium plates. Int J of solids and structures.2007; 44:3411-3439.

[10] Jena P K, Ramanjeneyulu K, Kumar K S, Bhat T B. Ballistic studies on layered structures. Materials and design 2009; 30:19221929.

[11] Børvik T, Hopperstad OS, Langseth M, Malo KA. Effect of target thickness in Blunt projectile penetration of Weldox 460 E steel plates. Int J Impact Eng 2003; 28:413-64.

[12] Gupta N K, Madhu V. An experimental study of normal and oblique impact of hard-core projectile on single and multi-layered plates. Int J Impact Eng. 1997; 27: 395-414.

[13] Wei Z, Y Deng, S Cao Zong, Gang W. Experimental investigation on the ballistic performance of monolithic and layerd metal plates subjected to impact by blunt rigid projectiles. Int J Impact Eng. 2012; 49:115-129.

[14] Deng Y, Zhang W, Cao Z. Experimental investigation on the ballistic performance of monolithic and layerd metal plates against ogival-nosed rigid projectiles. Mater Des. 2013; 44:228-239.

[15] El-Magd E, Abouridouane A. Characterization, modeling and simulation of deformation and fracture behaviour of the light weight wrought alloys under high strain rate loading. Int J Impact Eng. 2006; 32: 741-758. 
[16] Borvik T, Dey S, Clausen A H. Perforation resistance of five different high strength steel plates subjected to small arm projectiles. Int J of Impact Eng 2009; 36:948-964.

[17] Lee W S, Sue W C, Lin C F, Wu C J. The strain rate and temperature dependence of the dynamic impact properties of 7075 aluminium alloy. J Mater Process Tech. 2000; 100: 116-122.

[ 18] Teng X, Wierzbicki T, Huang M. Ballistic resistance of double-layered armor plates. Int J Impact Eng 2008; 35:870-84.

[19] Alavi Nia A, Hoseini GR. Experimental study of perforation of multi-layered targets by hemispherical-nosed projectiles. Mater Des $2011 ; 32(2): 1057-65$.

[20] Saleh M, Edwards L. Evaluation of a hydrocode in modelling NATO threats against steel armour. In: $25^{\text {th }}$ international symposium on ballistics, Beijing, China, 2010.

Fig.1 (a) Finite element model of projectile and target (b) material modeling

Fig. 2 Variation of residual velocity with element aspect ratio

Fig.3 Variation of residual velocity with number of elements over the target thickness

Fig.4 Perforation stages of spaced type plates impacted by hemispherical projectile at $118 \mathrm{~m} / \mathrm{s}$.

Fig.5 Plot of material state in the monolithic target (T4) impacted by hemispherical projectile at $118 \mathrm{~m} / \mathrm{s}$.

Fig.6 Perforation stages of spaced type plates $\left(T_{2}(1) T_{1}(5) T_{3}\right)$ impacted by hemispherical projectile at 118 $\mathrm{m} / \mathrm{s}$.

Fig.7 Perforation stages of spaced type plates $\left(T_{2}(1) T_{1}(5) T_{3}\right)$ impacted by hemispherical projectile at 126 $\mathrm{m} / \mathrm{s}$.

Fig.8 Material modeling of spaced type plates $\left(T_{2}(4) T_{1}(2) T_{3}\right)$ impacted by hemispherical

Fig.9 Perforation stages of spaced type plates $\left(T_{2}(4) T_{1}(2) T_{3}\right)$ impacted by hemispherical projectile at 122 $\mathrm{m} / \mathrm{s}$.

Fig.10 Perforation stages of spaced type plates $\left(T_{2}(5) T_{1}(1) T_{3}\right)$ impacted by hemispherical projectile at 113 $\mathrm{m} / \mathrm{s}$.

Fig.11 Perforation stages of spaced type plates $\left(\mathrm{T}_{2}(1) \mathrm{T}_{1}(5) \mathrm{T}_{3}\right)$ impacted by hemispherical projectile at 113 $\mathrm{m} / \mathrm{s}\left(30^{0}\right.$ Obliquity).

Fig.12 (a) Failure modes of Aluminium plate of T1 at various impact angles of TIT2T3

(b) Failure modes of Aluminium plate of T3 at an impact angle of $30^{\circ}$ of TIT2T3

Fig.13 Residual velocity and kinetic energy profiles of T3T2T1 target plate at $120 \mathrm{~m} / \mathrm{s}$ velocity

Fig.14 Plastic work and internal energy profiles of T3T2T1 target plate

Fig.15 Residual velocity vs initial velocity for target 1

Fig.16 Residual velocity vs initial velocity for target 11

Fig.17 Variation of the plastic deformation for spaced type plates T1T2T3 impacted by hemispherical projectile at $113 \mathrm{~m} / \mathrm{s}$.

Fig.18 Variation of the plastic deformation for spaced type plates T3T2T1 impacted by hemispherical projectile at $113 \mathrm{~m} / \mathrm{s}$.

Fig.19 Variation of the plastic deformation for spaced type plates $\left(T_{2}(5) T_{1}(1) T_{3}\right)$ impacted by hemispherical projectile at $113 \mathrm{~m} / \mathrm{s}$.

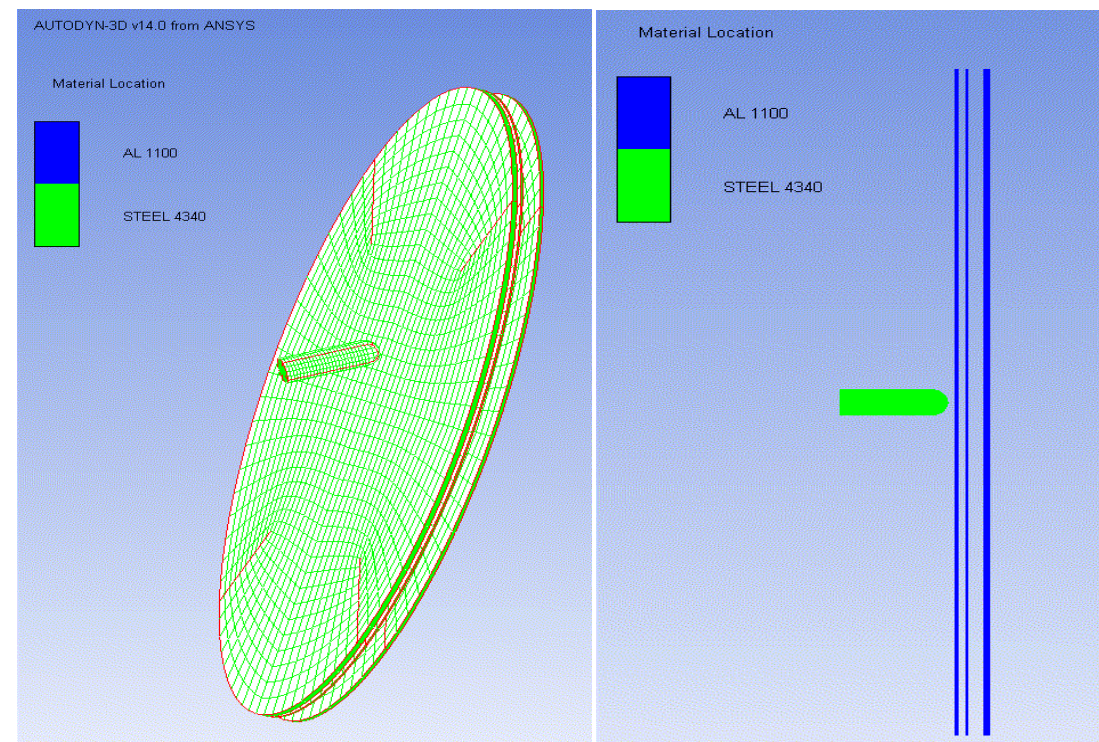

Fig.1 (a) Finite element model of projectile and target (b) material modeling 


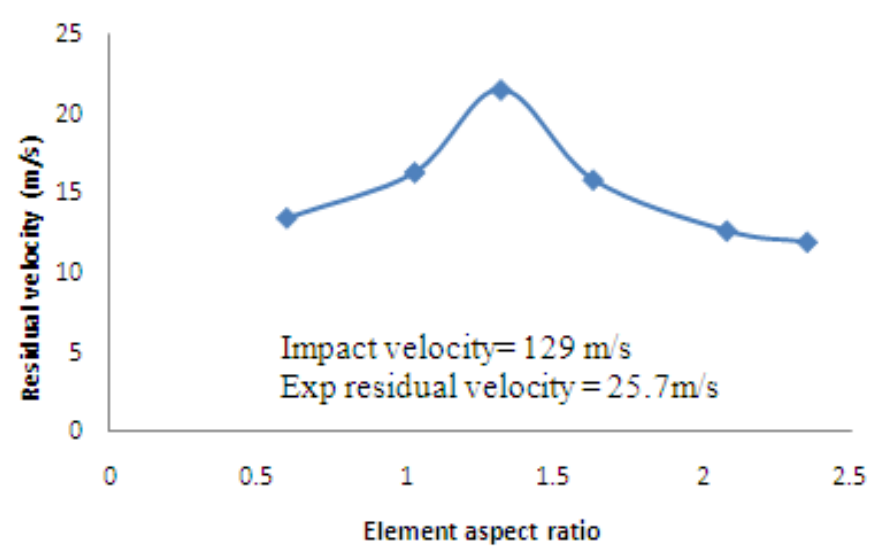

Fig.2 Variation of residual velocity with element aspect ratio

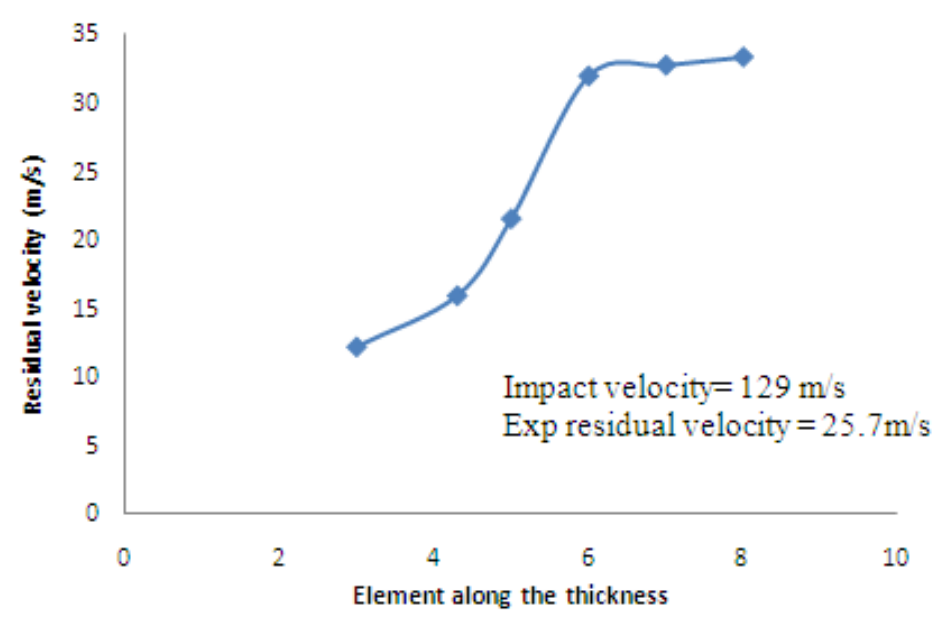

Fig.3 Variation of residual velocity with number of elements over the target thickness

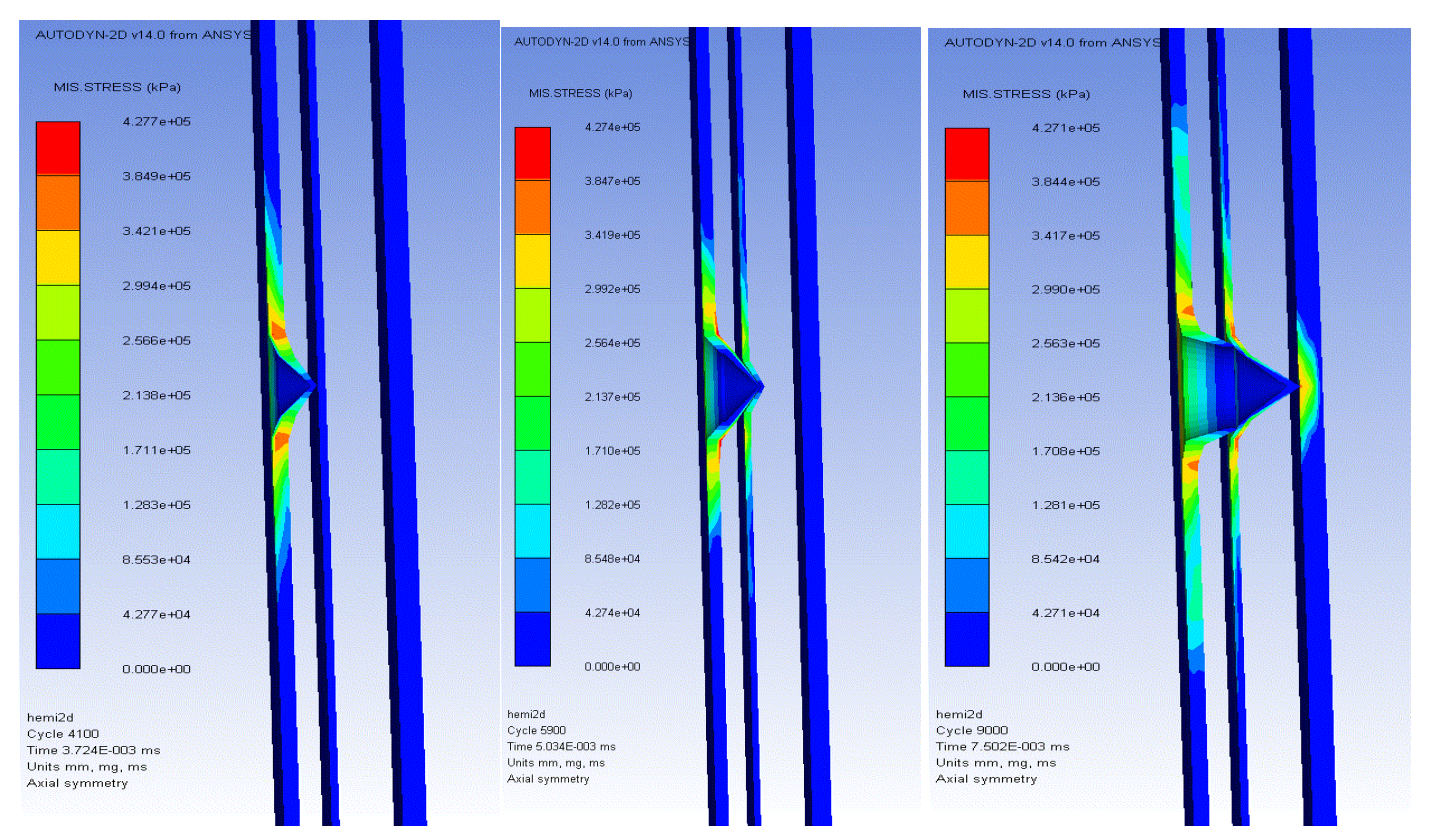



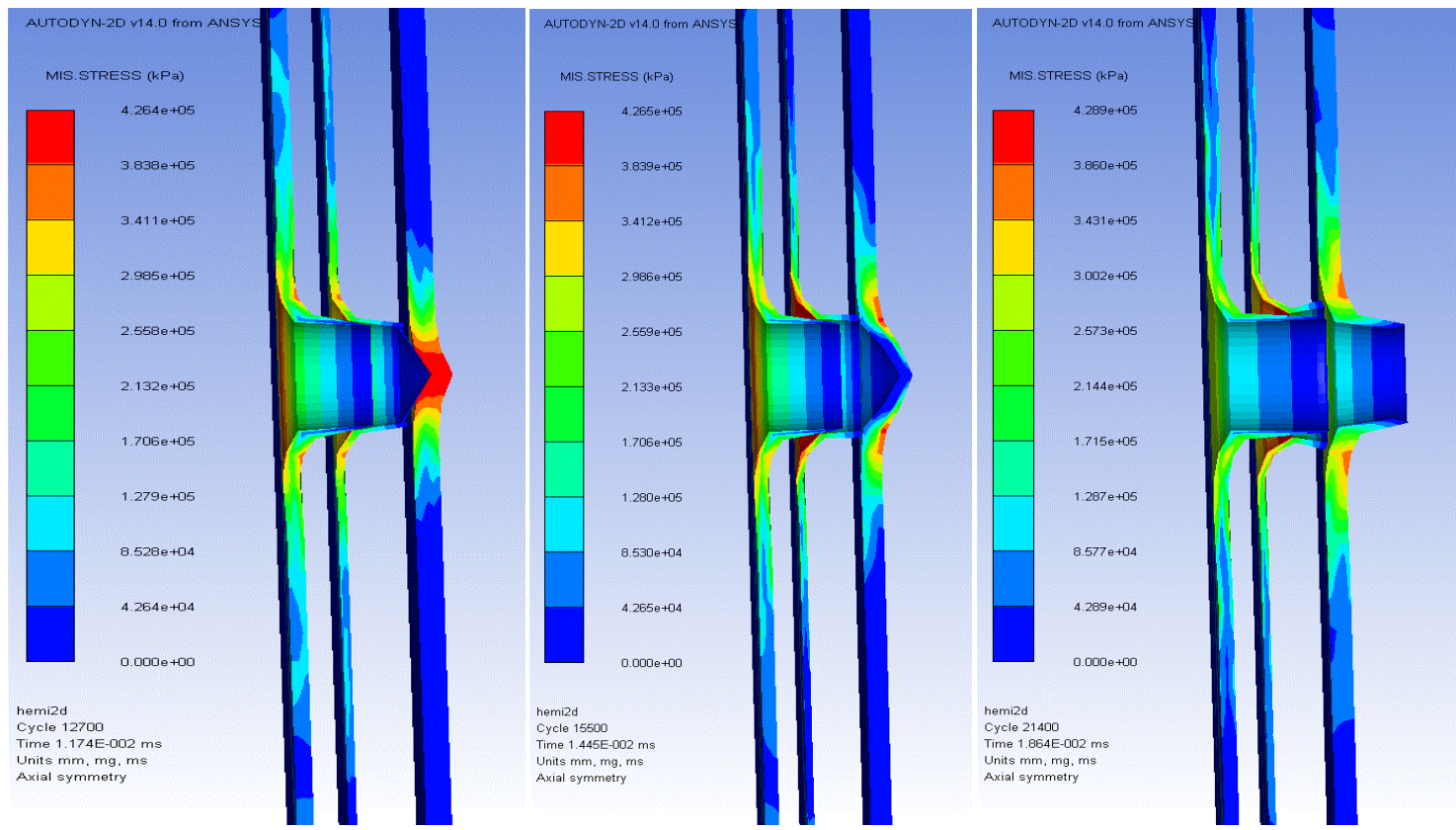

Fig.4 Perforation stages of spaced type plates impacted by hemispherical projectile at $118 \mathrm{~m} / \mathrm{s}$.
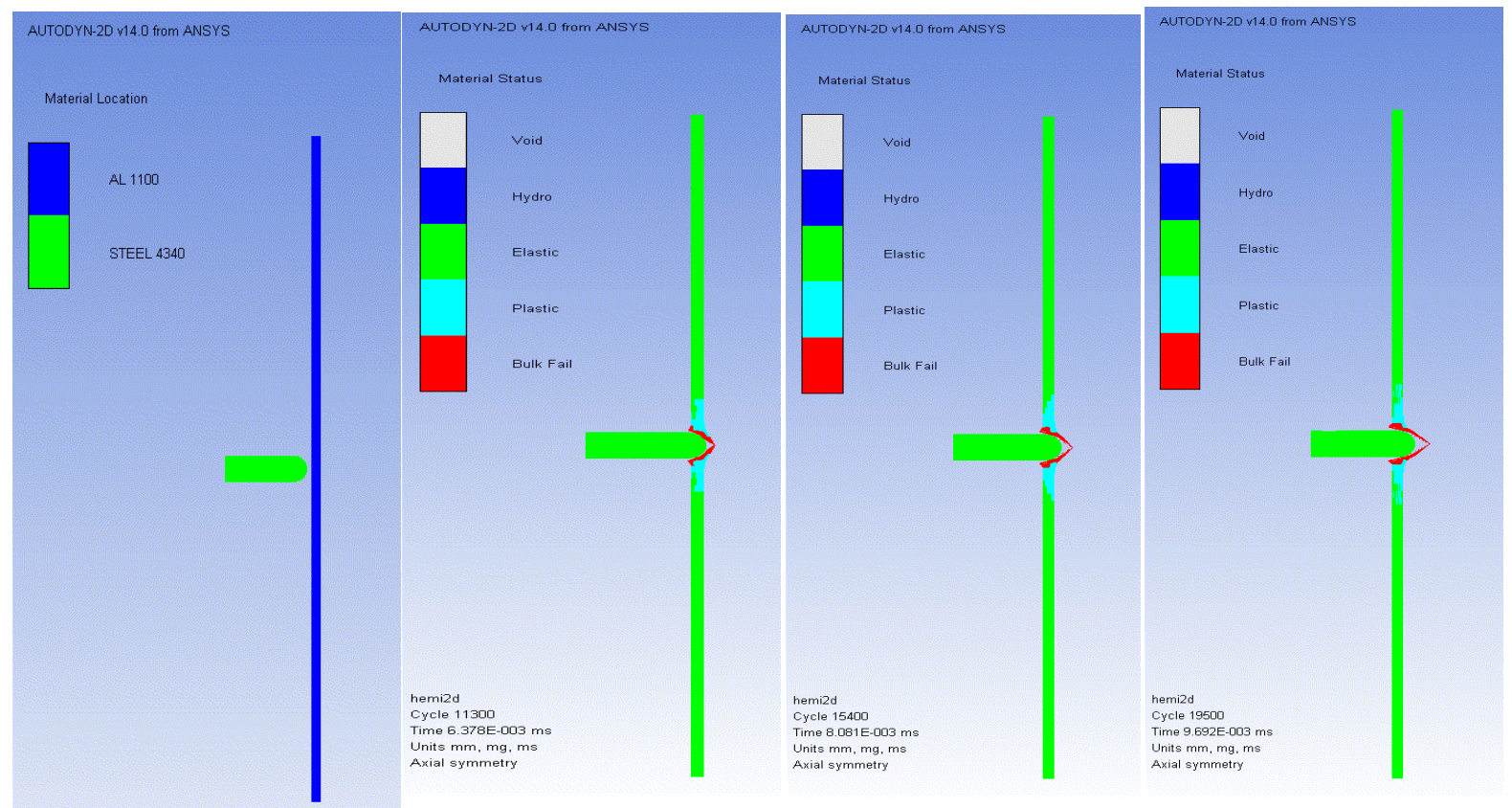

Fig.5 Plot of material state in the monolithic target (T4) impacted by hemispherical projectile at $118 \mathrm{~m} / \mathrm{s}$. 


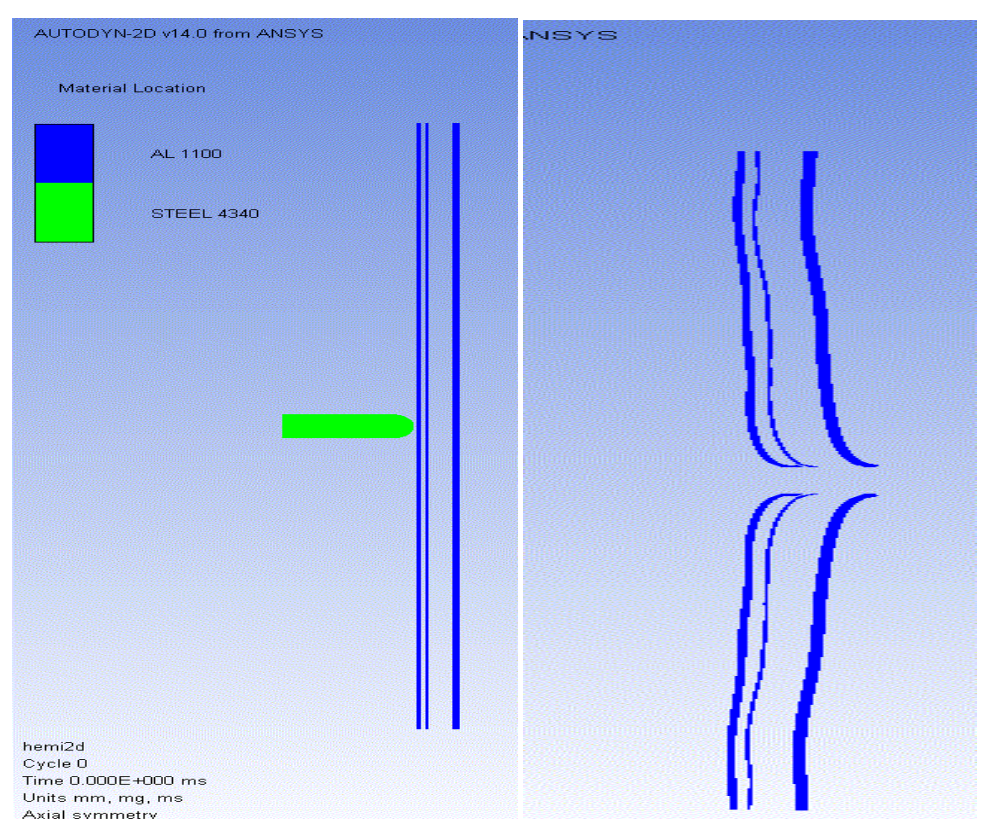

Fig.6 Perforation stages of spaced type plates $\left(T_{2}(1) T_{1}(5) T_{3}\right)$ impacted by hemispherical projectile at 118 $\mathrm{m} / \mathrm{s}$.
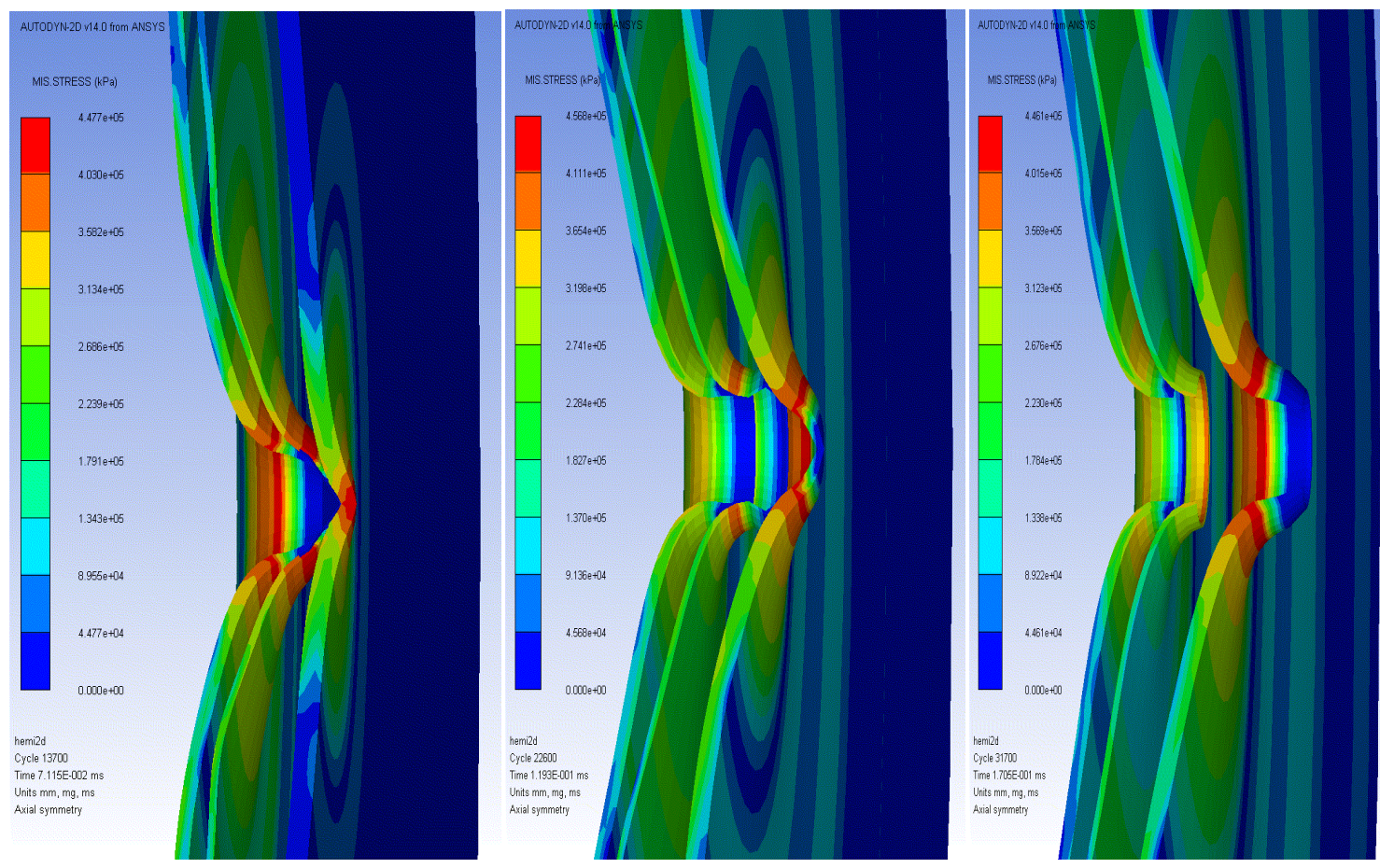

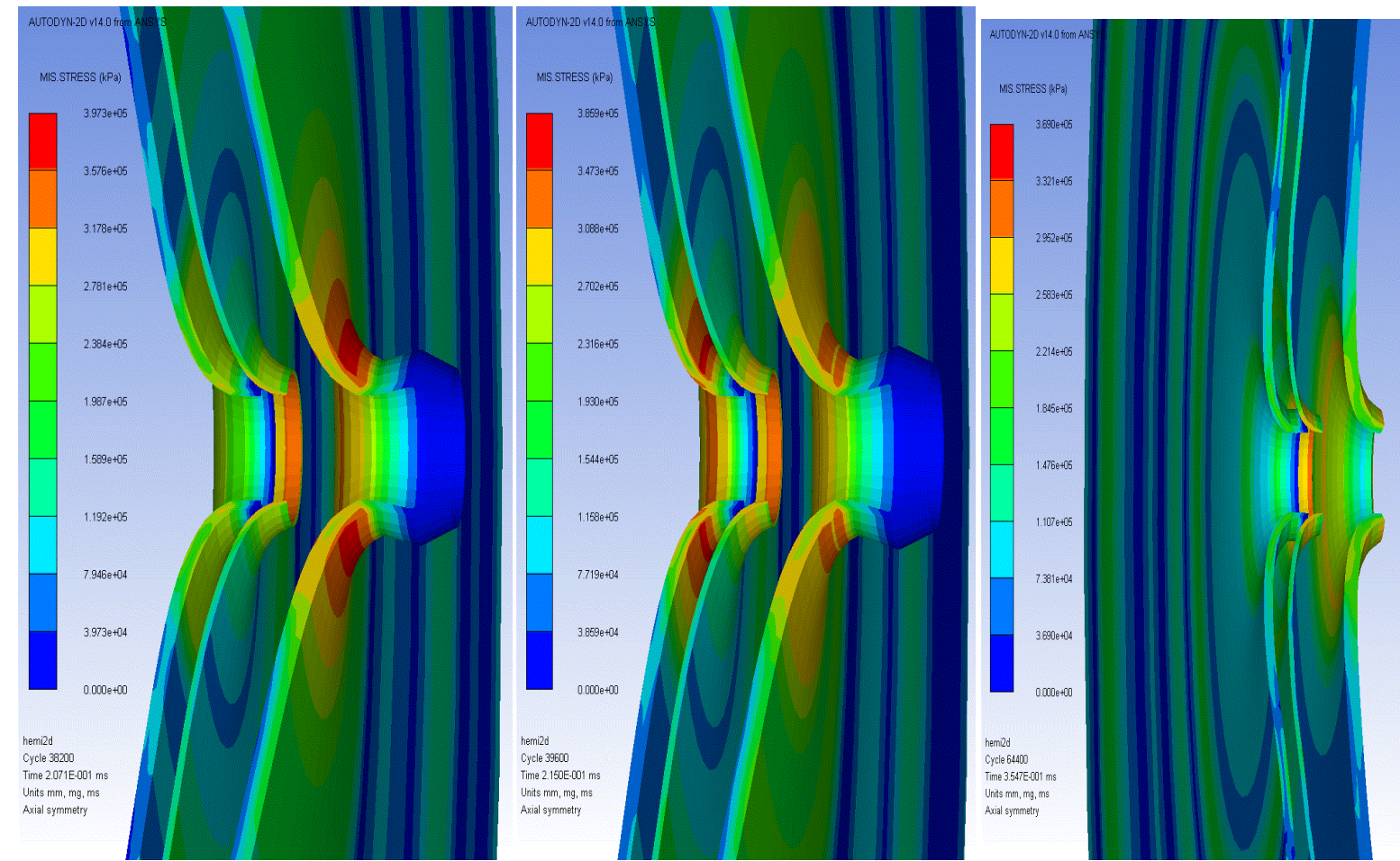

Fig.7 Perforation stages of spaced type plates $\left(T_{2}(1) T_{1}(5) T_{3}\right)$ impacted by hemispherical projectile at 126 $\mathrm{m} / \mathrm{s}$.
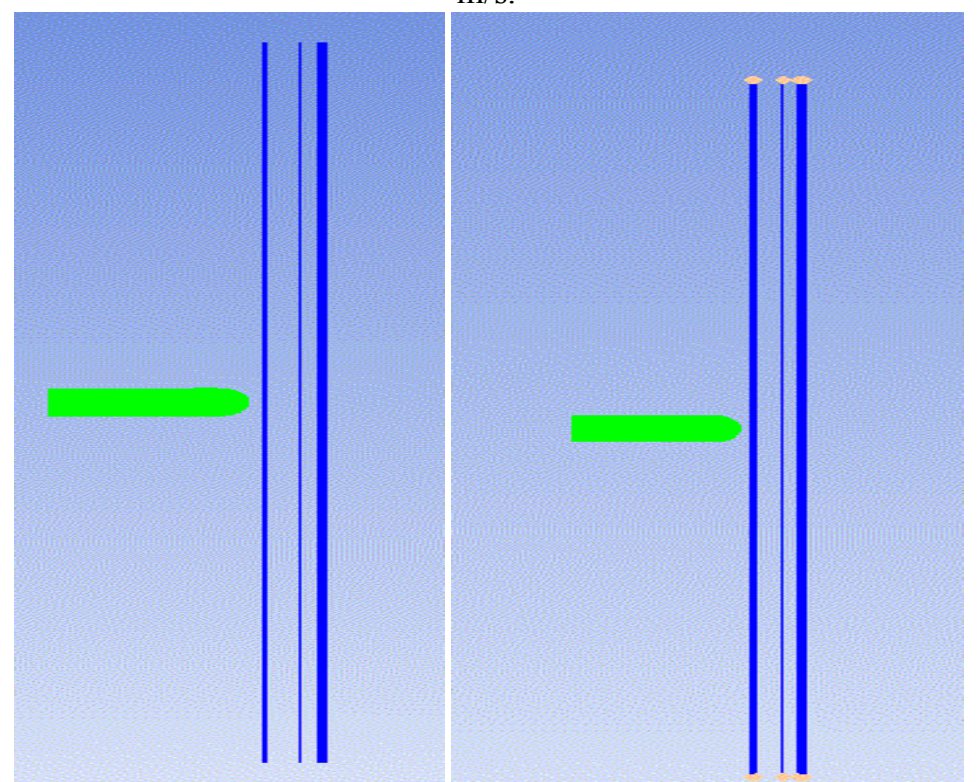

Fig.8 Material modeling of spaced type plates $\left(T_{2}(4) T_{1}(2) T_{3}\right)$ impacted by hemispherical projectile at 122 $\mathrm{m} / \mathrm{s}$. 

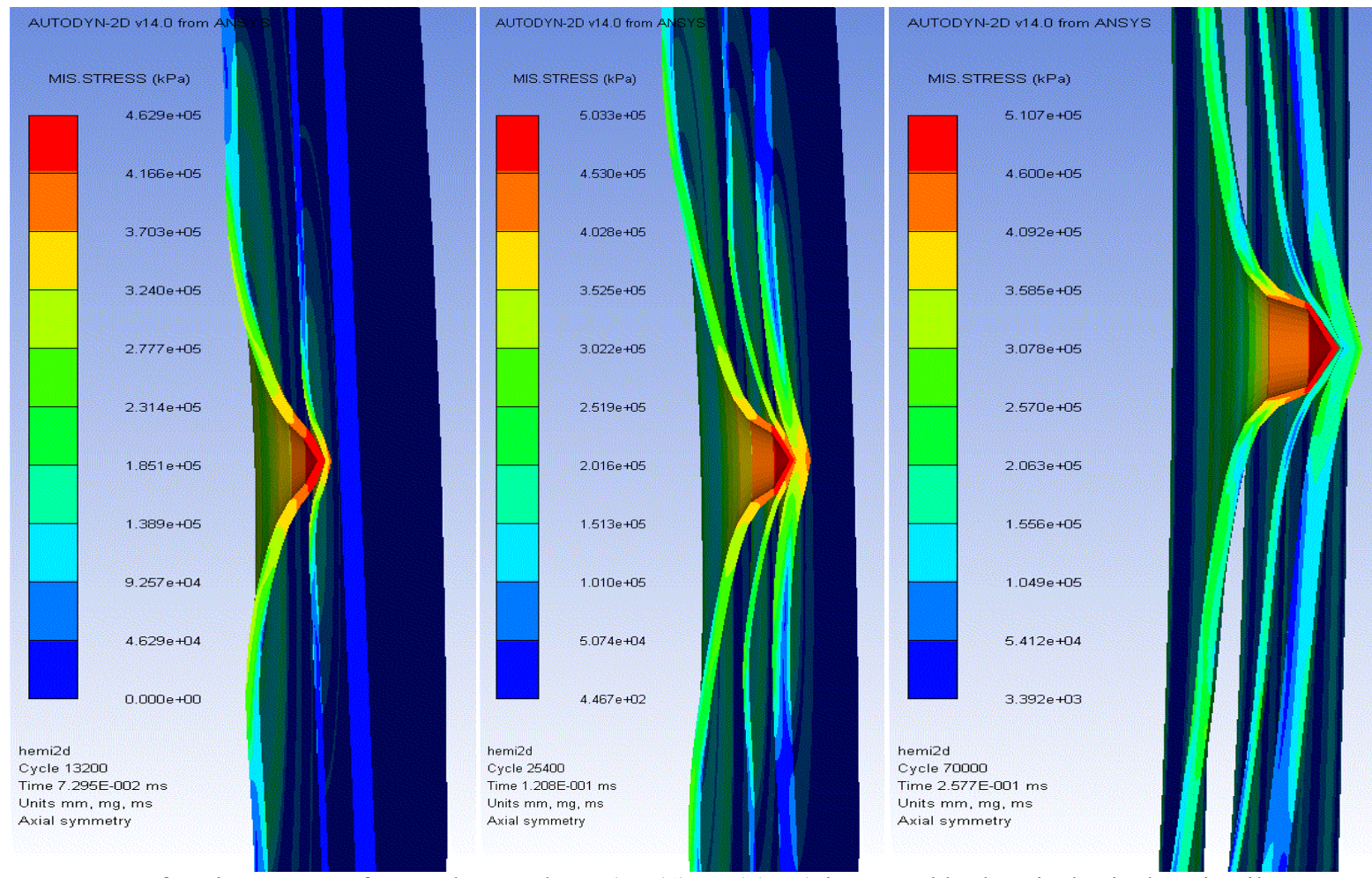

Fig.9 Perforation stages of spaced type plates $\left(T_{2}(4) T_{1}(2) T_{3}\right)$ impacted by hemispherical projectile at 122 $\mathrm{m} / \mathrm{s}$.

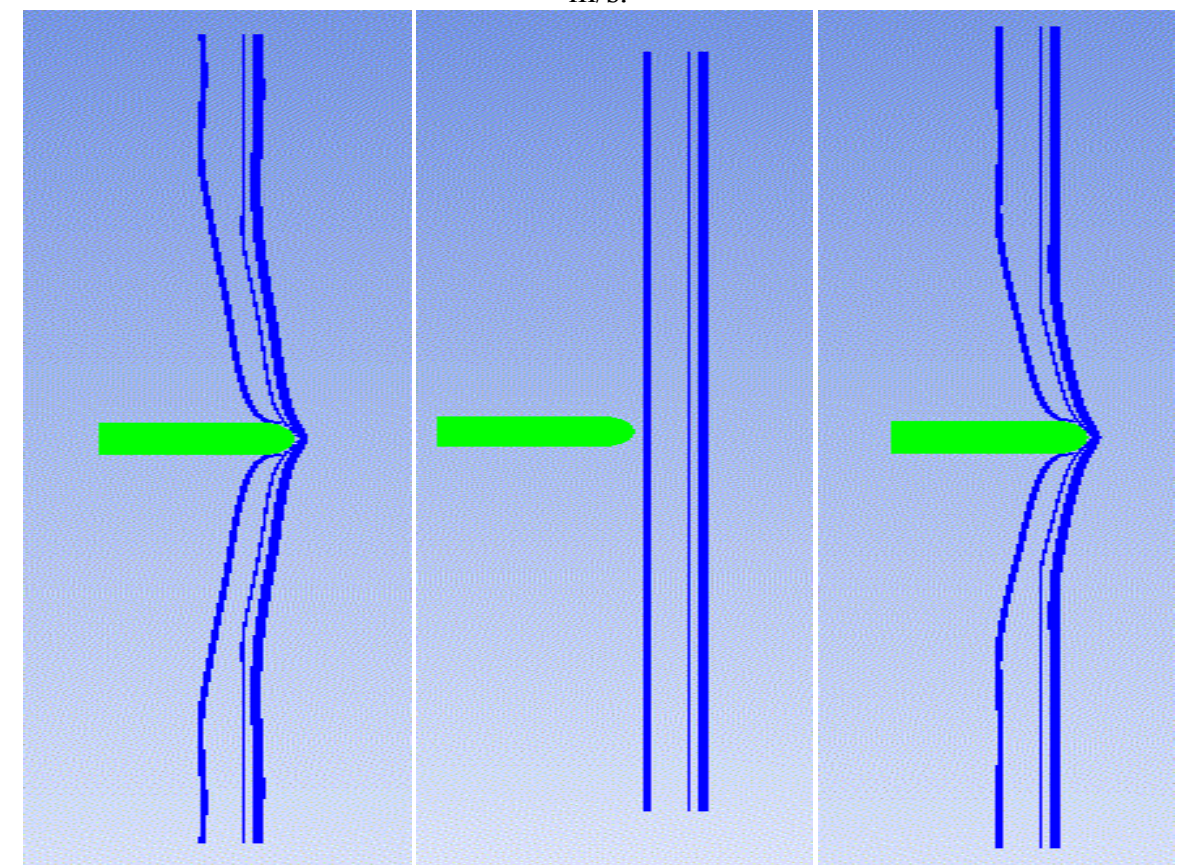

Fig.10 Perforation stages of spaced type plates $\left(T_{2}(5) T_{1}(1) T_{3}\right)$ impacted by hemispherical projectile at 113 $\mathrm{m} / \mathrm{s}$. 

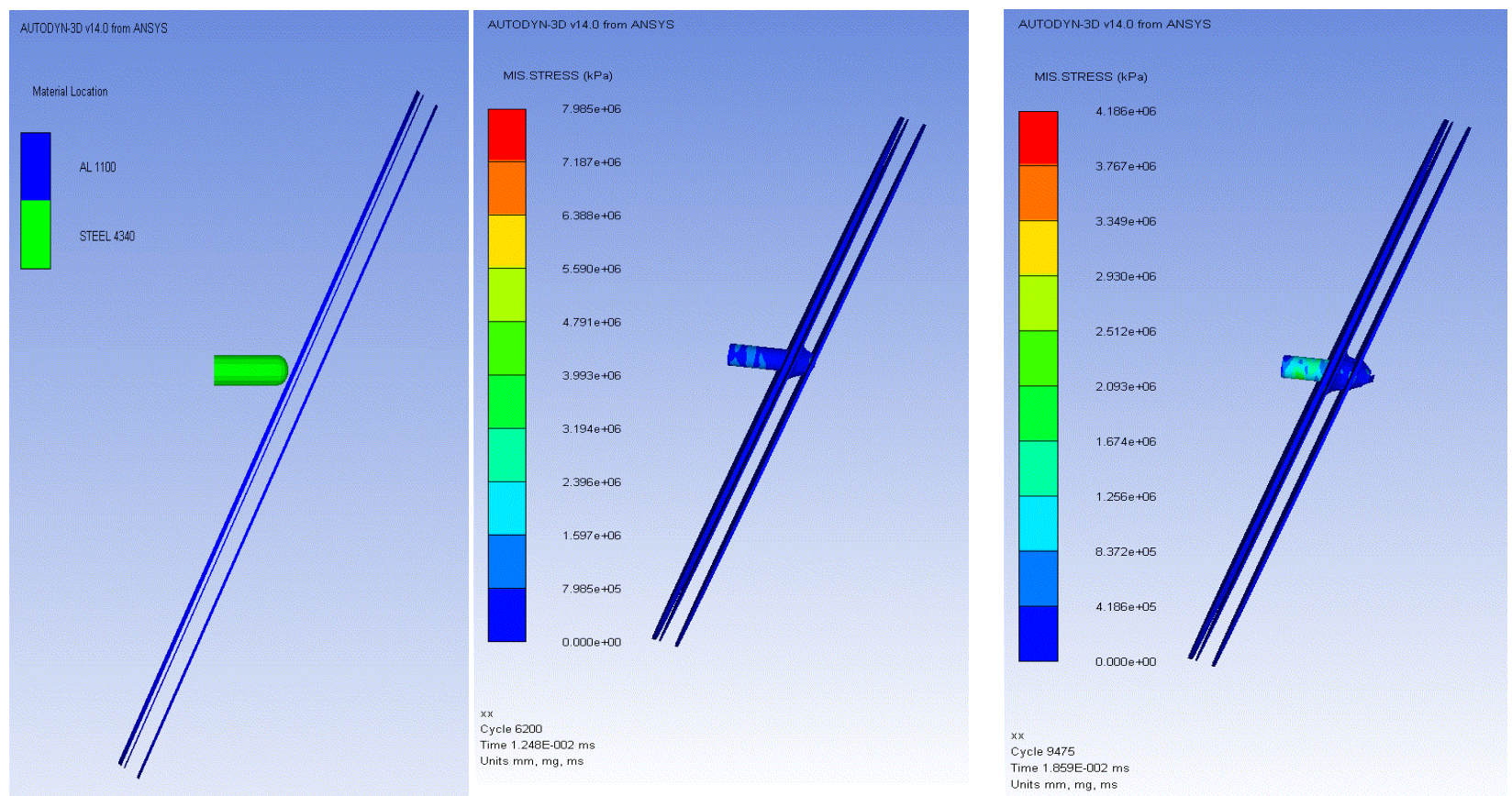

Fig.11 Perforation stages of spaced type plates $\left(T_{2}(1) T_{1}(5) T_{3}\right)$ impacted by hemispherical projectile at 113 $\mathrm{m} / \mathrm{s}\left(30^{0}\right.$ Obliquity).
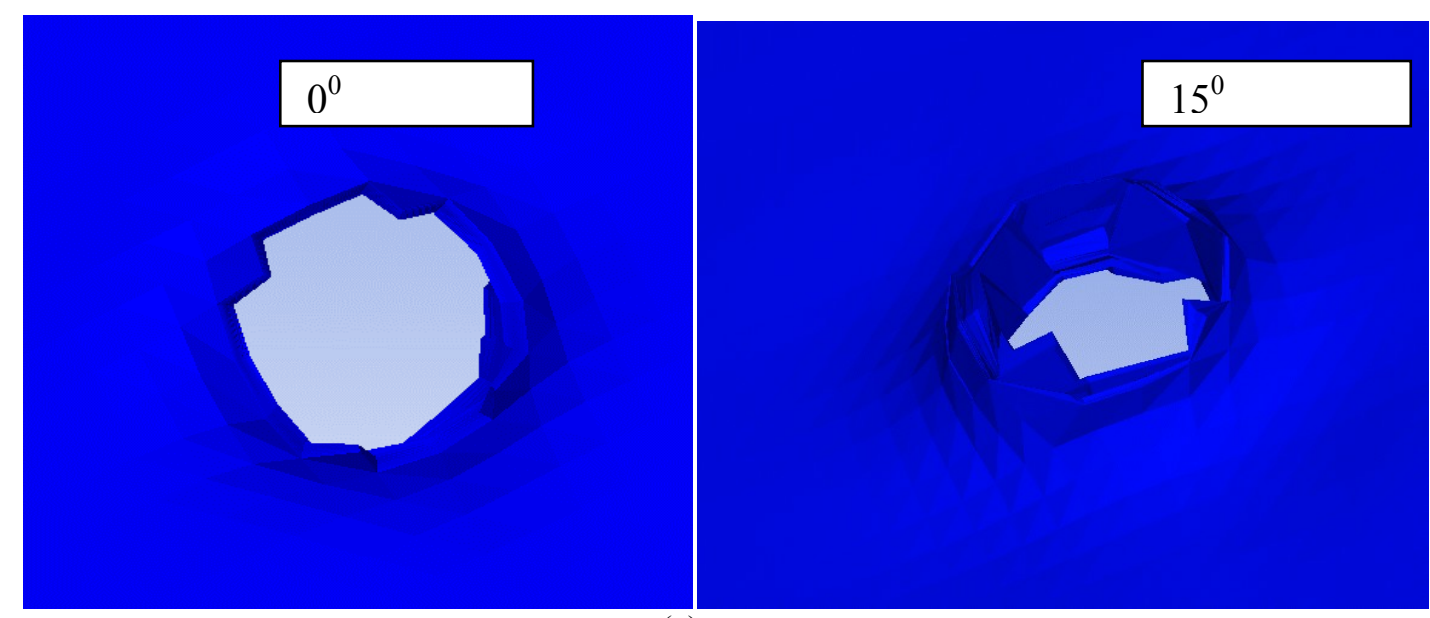

(a)

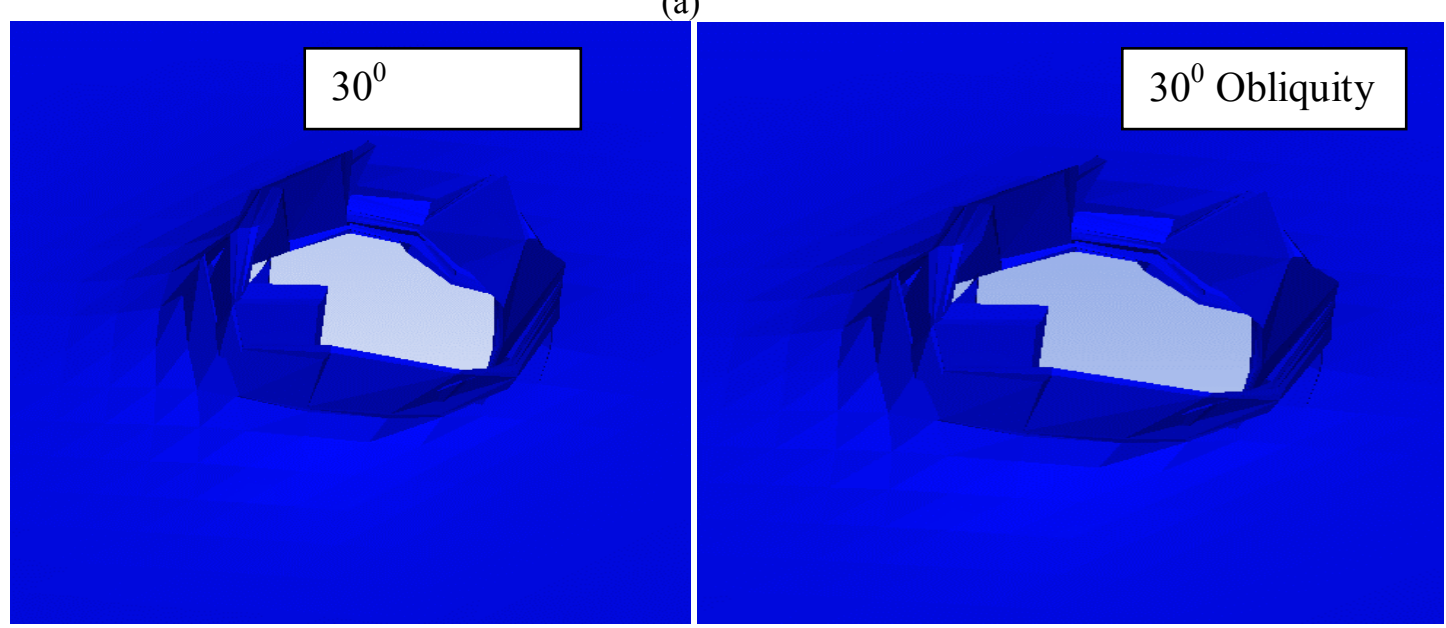

(b)

Fig.12 (a) Failure modes of Aluminium plate of $\mathrm{T} 1$ at various impact angles of TIT2T3 (b) Failure modes of Aluminium plate of T3 at an impact angle of $30^{\circ}$ of TIT2T3 


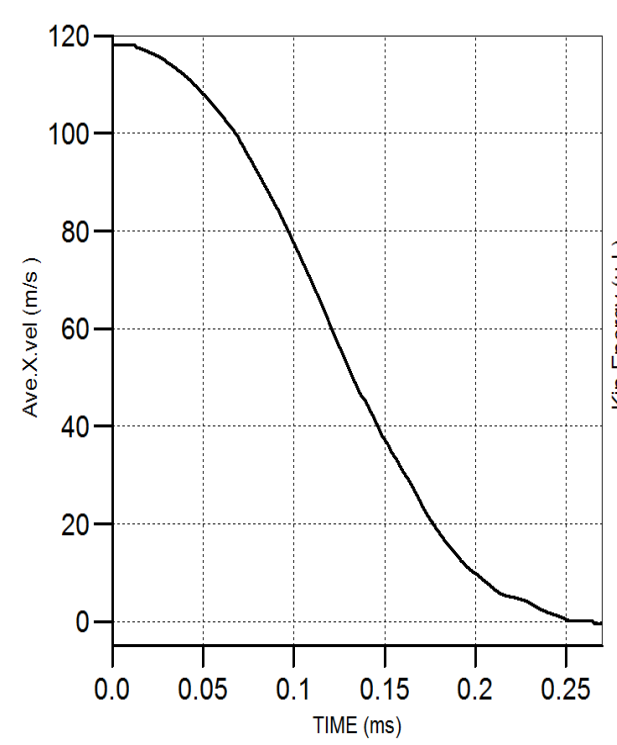

(a)

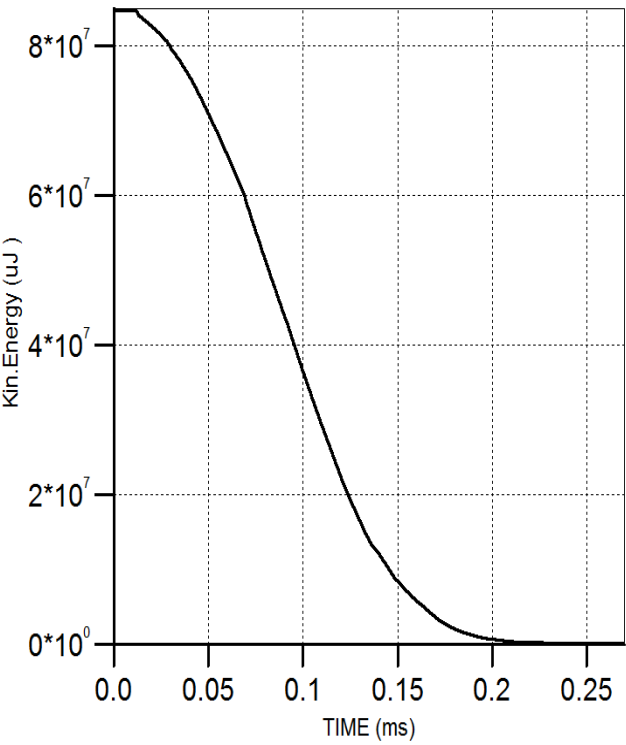

(b)

Fig.13 Residual velocity and kinetic energy profiles of T3T2T1 target plate at $120 \mathrm{~m} / \mathrm{s}$ velocity

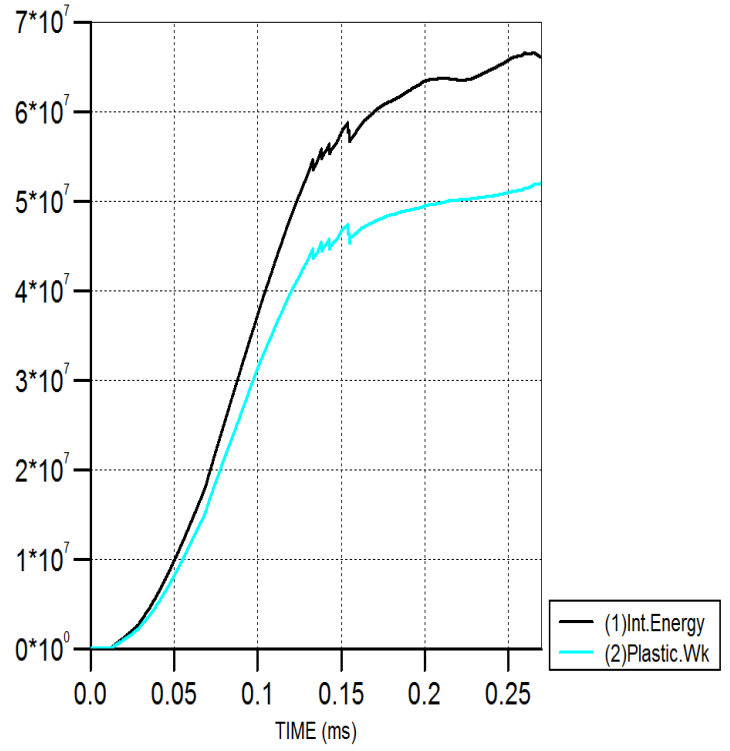

(a) At $110 \mathrm{~m} / \mathrm{s}$ velocity

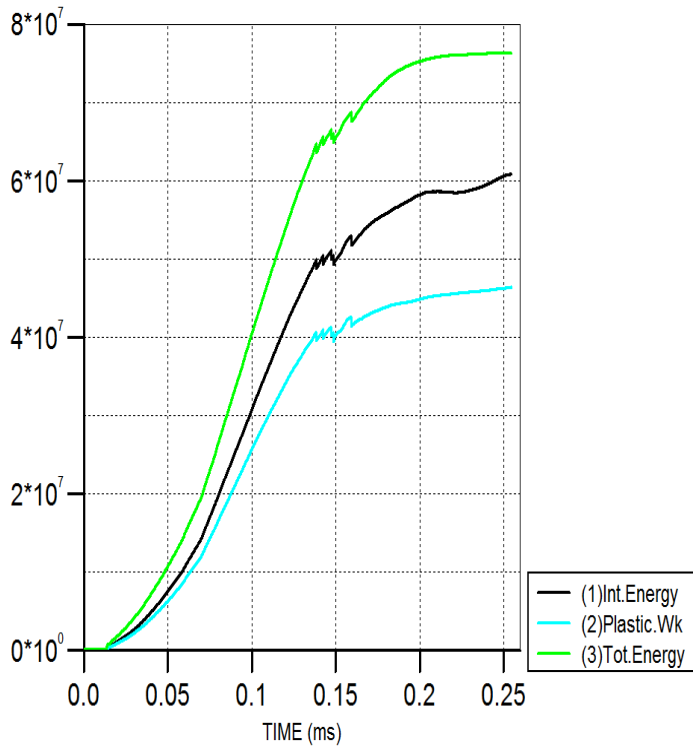

(b) At $115 \mathrm{~m} / \mathrm{s}$ velocity

Fig.14 Plastic work and internal energy profiles of T3T2T1 target plate

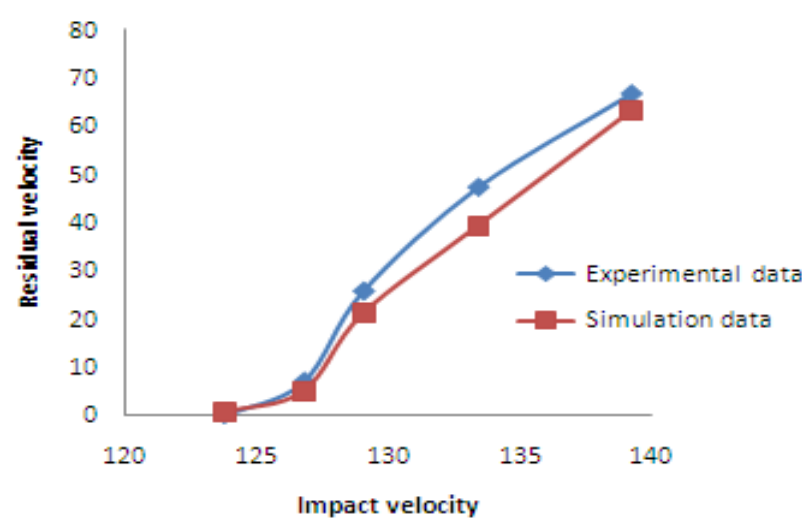

Fig.15 Residual velocity vs initial velocity for target 1 


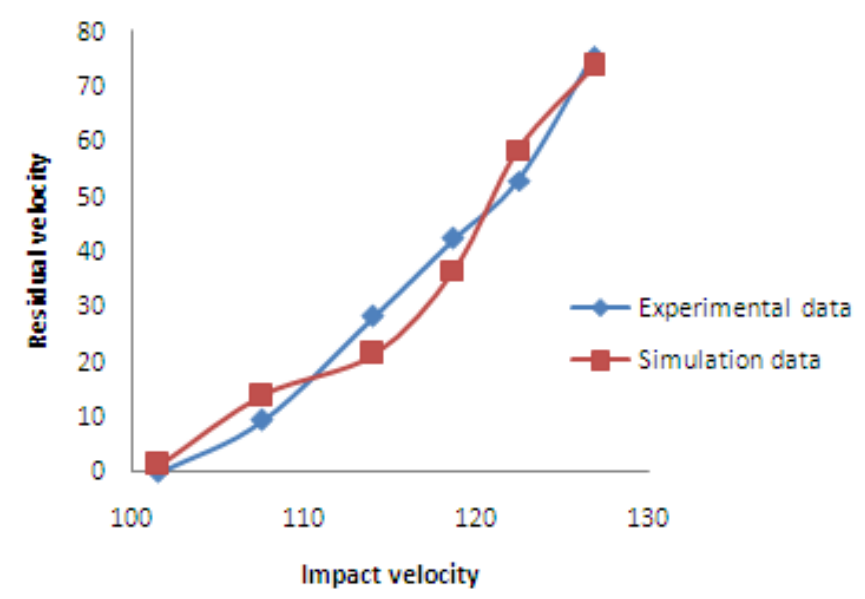

Fig.16 Residual velocity vs initial velocity for target 11

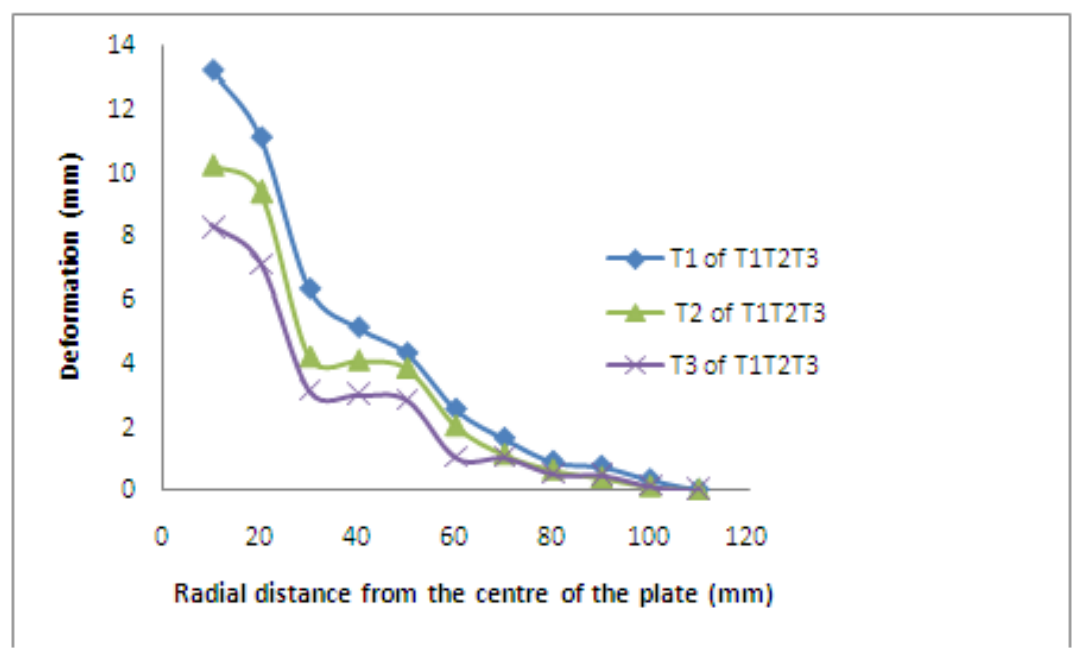

Fig.17 Variation of the plastic deformation for spaced type plates T1T2T3 impacted by hemispherical projectile at $113 \mathrm{~m} / \mathrm{s}$.

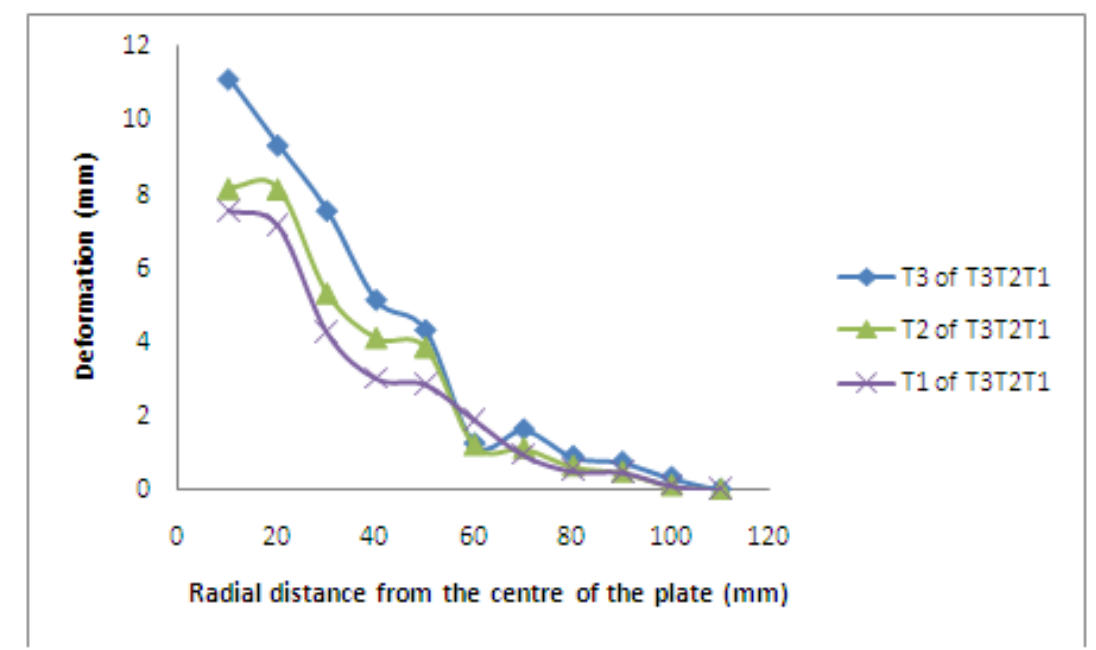

Fig.18 Variation of the plastic deformation for spaced type plates T3T2T1 impacted by hemispherical projectile at $113 \mathrm{~m} / \mathrm{s}$. 


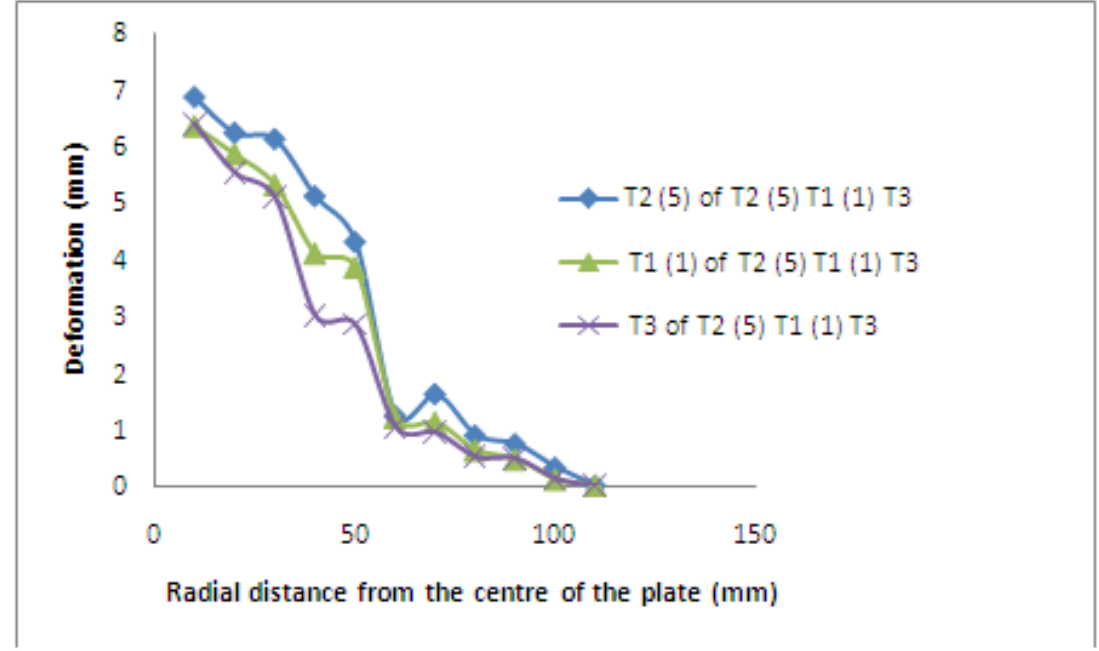

Fig.19 Variation of the plastic deformation for spaced type plates $\left(T_{2}(5) T_{1}(1) T_{3}\right)$ impacted by hemispherical projectile at $113 \mathrm{~m} / \mathrm{s}$.

Table 1- Target layer codes

Table 2- Experimental and numerical results of hemispherical nosed projectile impacted on Al 1100 target of in-contact type.

Table 3- Experimental and numerical results of hemispherical nosed projectile impacted on Al 1100 target of spaced type.

Table 1 .- Target layer codes

\begin{tabular}{|l|l|}
\hline Layer thickness $(\mathrm{mm})$ & Layer code \\
\hline $\mathrm{t}=0.5$ & $\mathrm{~T} 1$ \\
$\mathrm{t}=1.0$ & $\mathrm{~T} 2$ \\
$\mathrm{t}=1.5$ & $\mathrm{~T} 3$ \\
$\mathrm{t}=3.0$ & $\mathrm{~T} 4$ \\
\hline
\end{tabular}

Table 2.- Experimental and numerical results of hemispherical nosed projectile impacted on Al 1100 target of in-contact type.

\begin{tabular}{|c|c|c|c|c|c|}
\hline \multicolumn{6}{|c|}{ Hemispherical nosed projectile (Diameter $=8.7 \mathrm{~mm}$, Mass $=12.15$ grams $)$} \\
\hline \multicolumn{3}{|c|}{$\begin{array}{l}\text { Experimental Results } \\
\text { (Alavi Nia et al [19] }\end{array}$} & \multicolumn{3}{|c|}{ Numerical Results of Present Investigation } \\
\hline \multicolumn{3}{|c|}{ Normal Impact } & \multicolumn{3}{|c|}{$\begin{array}{l}\text { Triple layered target of in-contact type } \\
0^{0} \text { oblique angle } 15^{\circ} \text { oblique angle } 30^{\circ} \text { oblique angle }\end{array}$} \\
\hline Target code & $\mathrm{V}_{\mathrm{i}}(\mathrm{m} / \mathrm{s})$ & $\mathrm{V}_{\mathrm{r}}(\mathrm{m} / \mathrm{s})$ & $\begin{array}{l}V_{\mathrm{r}} \\
(\mathrm{m} / \mathrm{s})\end{array}$ & $\begin{array}{l}\mathrm{V}_{\mathrm{r}} \\
(\mathrm{m} / \mathrm{s})\end{array}$ & $\begin{array}{l}\mathrm{V}_{\mathrm{r}} \\
(\mathrm{m} / \mathrm{s})\end{array}$ \\
\hline \multirow[t]{4}{*}{$\mathrm{T} 4$} & 139.18 & 66.7 & 63.14 & 58.32 & 52.14 \\
\hline & 133.26 & 47.3 & 39.24 & 33.65 & 31.56 \\
\hline & 129 & 25.7 & 21.01 & 18.34 & 13.87 \\
\hline & 126.74 & 6.96 & 4.87 & 0 & 0 \\
\hline \multirow[t]{4}{*}{ T1T2T3 } & 139.18 & 85.25 & 81.34 & 75.62 & 67.45 \\
\hline & 133.36 & 62 & 58.72 & 53.64 & 48.67 \\
\hline & 126.74 & 50.5 & 53.46 & 44.31 & 38.54 \\
\hline & 118.65 & 21.7 & 23.98 & 18.85 & 12.78 \\
\hline \multirow[t]{4}{*}{ T1T3T2 } & 139.18 & 84.67 & 88.64 & 82.14 & 74.87 \\
\hline & 133.36 & 75.133 & 72.54 & 64.68 & 59.37 \\
\hline & 126.74 & 51.6 & 54.68 & 48.35 & 42.14 \\
\hline & 122.4 & 36.3 & 39.54 & 32.98 & 27.68 \\
\hline \multirow[t]{5}{*}{ T2T1T3 } & 139.18 & 75.9 & 73.58 & 66.84 & 62.31 \\
\hline & 133.36 & 61.74 & 58.34 & 53.25 & 47.08 \\
\hline & 126.74 & 49.1 & 42.64 & 38.64 & 32.27 \\
\hline & 118.65 & 19 & 27.37 & 22.87 & 17.31 \\
\hline & 113.5 & 0 & 0 & 0 & 0 \\
\hline \multirow[t]{2}{*}{ T2T3T1 } & 133.36 & 74.3 & 78.65 & 72.64 & 64.27 \\
\hline & 126.74 & 46.3 & 41.34 & 36.74 & 31.78 \\
\hline
\end{tabular}


Numerical studies on perforation of multi-layered targets by hemispherical-nosed projectiles

\begin{tabular}{|l|l|l|l|l|l|}
\hline & 118.65 & 18.3 & 21.54 & 17.62 & 13.84 \\
\cline { 2 - 7 } & 113.95 & 0 & 2.45 & 0 & 0 \\
\hline \multirow{5}{*}{ T3TIT2 } & 139.18 & 71.15 & 75.67 & 68.34 & 61.34 \\
\cline { 2 - 6 } & 133.36 & 57 & 52.45 & 47.85 & 42.75 \\
\cline { 2 - 6 } & 126.74 & 39 & 35.75 & 29.67 & 22.38 \\
\cline { 2 - 6 } & 122.4 & 26.3 & 22.43 & 18.39 & 14.91 \\
\cline { 2 - 6 } & 118.65 & 0 & 0 & 0 & 0 \\
\hline \multirow{5}{*}{ T3T2T1 } & 139.18 & 68.8 & 62.54 & 62.54 & 55.17 \\
\cline { 2 - 6 } & 133.36 & 60.5 & 63.67 & 63.67 & 57.47 \\
\cline { 2 - 6 } & 126.74 & 41.3 & 44.42 & 44.42 & 37.49 \\
\cline { 2 - 6 } & 122.4 & 24.1 & 28.35 & 28.35 & 23.68 \\
\cline { 2 - 6 } & 119 & 0 & 0 & 0 & 0 \\
\hline
\end{tabular}

Table 3.- Experimental and numerical results of hemispherical nosed projectile impacted on Al 1100 target of spaced type.

\begin{tabular}{|c|c|c|c|c|c|}
\hline \multicolumn{6}{|c|}{ Hemispherical nosed projectile (Diameter $=8.7 \mathrm{~mm}$, Mass $=12.15$ grams $)$} \\
\hline \multicolumn{3}{|c|}{ Experimental Results(Alavi Nia et al [19] } & \multicolumn{3}{|c|}{ Numerical Results of Present Investigation } \\
\hline \multicolumn{3}{|c|}{ Normal Impact } & \multicolumn{3}{|c|}{$\begin{array}{l}\text { Triple layered target of spaced type } 0^{0} \text { oblique angle } \\
15^{0} \text { oblique angle } 30^{\circ} \text { oblique angle }\end{array}$} \\
\hline Target Number & $\begin{array}{l}\mathrm{V}_{\mathrm{i}} \\
(\mathrm{m} / \mathrm{s})\end{array}$ & $\begin{array}{l}\mathrm{V}_{\mathrm{r}} \\
(\mathrm{m} / \mathrm{s})\end{array}$ & $\begin{array}{l}\mathrm{V}_{\mathrm{r}} \\
(\mathrm{m} / \mathrm{s})\end{array}$ & $\begin{array}{l}\mathrm{V}_{\mathrm{r}} \\
(\mathrm{m} / \mathrm{s})\end{array}$ & $\begin{array}{l}\mathrm{V}_{\mathrm{r}} \\
(\mathrm{m} / \mathrm{s})\end{array}$ \\
\hline \multirow[t]{4}{*}{$\mathrm{T} 2(1) \mathrm{T} 1(5) \mathrm{T} 3$} & 126.74 & 62.1 & 64.62 & 58.54 & 52.18 \\
\hline & 122.4 & 39.6 & 36.12 & 31.37 & 25.45 \\
\hline & 118.65 & 29.6 & 25.42 & 22.75 & 16.34 \\
\hline & 113.95 & 9.35 & 7.25 & 2.14 & 0 \\
\hline \multirow[t]{4}{*}{$\mathrm{T} 2(2) \mathrm{T} 1(4) \mathrm{T} 3$} & 126.74 & 64 & 62.47 & 55.98 & 49.54 \\
\hline & 122.4 & 43.9 & 41.35 & 35.56 & 29.67 \\
\hline & 118.65 & 33.1 & 38.65 & 32.84 & 27.87 \\
\hline & 113.95 & 12.6 & 15.25 & 7.42 & 2.38 \\
\hline \multirow[t]{4}{*}{$\mathrm{T} 2$ (3)T1(3) T3 } & 126.74 & 69.7 & 62.84 & 57.24 & 49.58 \\
\hline & 122.4 & 48.2 & 45.98 & 38.98 & 32.49 \\
\hline & 118.65 & 39.1 & 32.47 & 27.48 & 23.62 \\
\hline & 113.95 & 17.3 & 21.6 & 16.94 & 12.53 \\
\hline \multirow[t]{4}{*}{$\mathrm{T} 2$ (4)T1(2) T3 } & 126.74 & 75.6 & 73.58 & 67.37 & 61.42 \\
\hline & 122.4 & 52.85 & 58.34 & 52.64 & 46.94 \\
\hline & 118.65 & 42.3 & 36.54 & 32.97 & 27.54 \\
\hline & 107.5 & 9.3 & 13.8 & 8.37 & 3.68 \\
\hline \multirow[t]{4}{*}{$\mathrm{T} 2$ (5)T1(1) T3 } & 126.74 & 76.3 & 80.21 & 74.21 & 66.45 \\
\hline & 122.4 & 54.1 & 51.32 & 45.34 & 38.35 \\
\hline & 118.65 & 44.5 & 48.82 & 43.69 & 37.12 \\
\hline & 113.95 & 31 & 33.57 & 25.97 & 18.27 \\
\hline
\end{tabular}

